\title{
Feeding Reduced the Absorption of Erythromycin in the Dog
}

Erythromycin is often used in small animal practice for skin and respiratory tract infections. Erythromycin is an acid-labile organic base (pKa 8.8) which inhibits protein synthesis mainly in gram-positive organisms. To protect erythromycin against gastric acid, it is usually administered as an enterotablet or combined chemically with an ester. The Serum Minimal Inhibitory Values (MIC) are (0.19-) 0.25-0.32 $\mu \mathrm{g} / \mathrm{ml}$. Gastrointestinal side-effects including diarrhea, nausea, and vomiting are common both in humans and dogs. As with several drugs registered for oral administration in veterinary medicine, minimal information is available about the pharmacokinetics of the drug and factors affecting it. The stimulus for the present study was the introduction of erythromycin acistrate (EA) for human use on the Finnish drug market. EA is shown to produce less harmful side-effects and to have a better absorption compared to traditional erythromycin formulations. Oral dosing of EA to dog produces very few side-effects, but absorption is also poor when given with food (Eriksson \& Mero 1988, unpublished data). Based on this information it was suspected that feeding reduces the absorption of erythromycin from the intestine compared to dosing without food.

A single oral dose of erythromycin was given to 8 dogs. The tested preparations were EA as a film-coated tablet $\left(\right.$ Erasis $^{\circledR}{ }^{\circledR} 200$ $\mathrm{mg}$, Orion), EA as coated granules in mixture (test product, Orion), erythromycin stearate (ES) as a tablet (Abboticin ${ }^{\circledR} 250 \mathrm{mg}$, Abbot), and erythromycin (Erythromycin ${ }^{\circledR}$
$250 \mathrm{mg}$, Upjohn) as an enterotablet (EE). There were 2 dogs in each drug group. In the first part of the study the animals were fasted for $12 \mathrm{~h}$ prior to dosing and up to $6 \mathrm{~h}$ after. In the second part 2 weeks later, the animals were fed a normal meal (rice, meat, and pellets) in connection with dosing. The same dogs received the same drug in both parts of the study, and all the circumstances were similar. All drugs were given at a dose of $20 \pm 1 \mathrm{mg} / \mathrm{kg}$. Blood samples were taken at $0,1,2,4,8,12$, and $24 \mathrm{~h}$. The blood was centrifuged, serum was refrigerated and frozen within $24 \mathrm{~h}$ and kept frozen until analysis. For analyzing the serum erythromycin concentrations a microbiological diffusion assay method on large plates was used according to Bennet et al. (1966). Bacillus subtilis, ATCC 6631 , was used as a test microbe, the sensitivity of which for the erythromycin base in serum is $0.08 \mu \mathrm{g} / \mathrm{ml}$. The erythromycin base, which was compared to the U.S.P. erythromycin base standard, was used as standard for samples were read on the standard curve.

The results are presented in Figs. 1 and 2 . The figures show that feeding decreases the absorption of all erythromycin compounds. Reliable therapeutic serum concentrations (MIC $>>0,32 \mu \mathrm{g} / \mathrm{ml}$ ) were not achieved with any drug when given with food. Factors causing variation in the serum absorption profiles are the following: the individual, the drug, its chemical and pharmaceutical formulation, and the subsequent administration of food, liquids or other drugs. The serum concentrations are here presented as a 


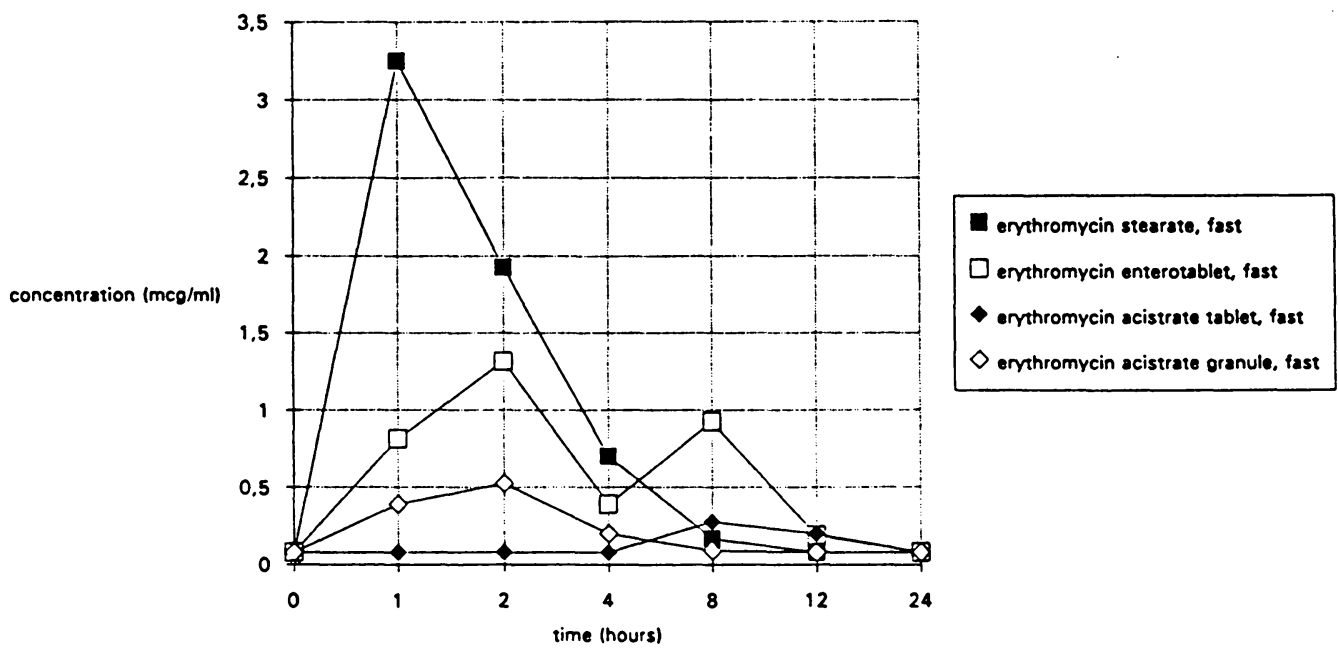

Figure 1. Mean serum concentrations $(\mathrm{mcg} / \mathrm{ml})$ of four different erythromycin compounds according to time (hours) after a single oral dose given without food to dogs.

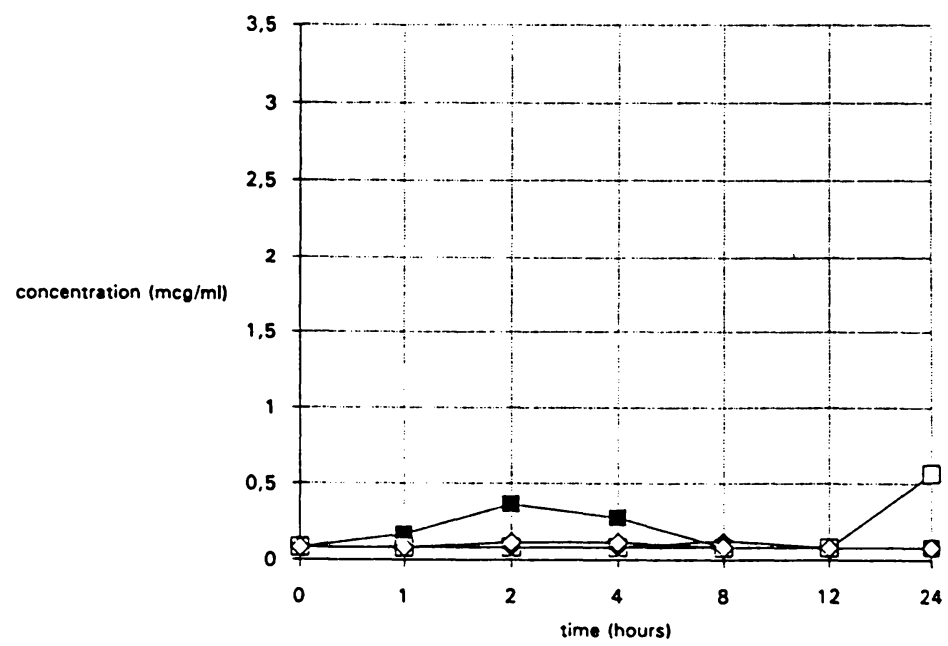

errthromycin stearate, food

Derythromycin enterotablet, food

- emthromycin acistrate tablet, food

$\checkmark$ erythromycin acistrate granule, food

Figure 2. Mean serum concentrations $(\mathrm{mcg} / \mathrm{ml})$ of four different erythromycin compounds according to time (hours) after a single oral dose given with food to dogs. 
mean of 2 dogs, due to minor individual differences, except for EE. The variation in the EE group is probably due to the enterotablet formulation, from which the release of the active compound is difficult to predict. Marvola et al. (1988) showed that enteric-coated tablets given with food remain from 6 to $8 \mathrm{~h}$ in the stomach. This can explain the peculiar peak of EE at $24 \mathrm{~h}$ in Fig. 2, which was actually the result in only 1 of the 2 dogs. The enteric coating had possibly been injured by chewing, resulting in the destruction of the erythromycin base in the stomach of the other dog. Chewing, which is difficult to prevent, leads in practice to an unreliable absorption of the drug. ES is absorbed well when dosed without food (Fig. $1)$, but as the tablets are usually better tolerated when given with food, the veterinarian may recommend dosing in connection with feeding. EA is absorbed poorly both with and without food and both as a tablet and mixture. As EA is well tolerated, it seems that part of the gastrointestinal side-effects are due to systemic effects. The reason for the poor absorption compared to humans requires further investigations.

The use of erythromycin in small animal practice is doubtful, since according to the results of the present investigation, erythromycin is not absorbed when given with food.

Anders Eriksson,

Veterinary Station Mevet, Helsinki, Finland.

Veikko Rauramaa,

Orion Pharmaceutica, Espoo, Finland.

Irmeli Happonen and Matti Mero,

College of Veterinary Medicine,

The Department of Clinical Sciences,

Helsinki, Finland.

References

Bennet JV, Brodie JL, Benner EJ, Kirby WMM: Simplified, accurate method for antibiotic assay of clinical specimens. Appl. Microbiol. 1966, 14, 170-177.

Marvola M, Heinämäki J, Westermarck E, Happonen I: The fate of single-unit enteric-coated drug products in the stomach of the dog. Acta Pharmaceutica Fennica 1986, 95, 59-70.

\section{(Received September 3, 1990; accepted November 5, 1990).}

Reprints may be requested from: Irmeli Happonen, College of Veterinary Medicine, Department of Clinical Sciences, Box 6, SF-00581 Helsinki, Finland. 